\title{
Materialize: Acervo Físico e Digital de Materiais da FAU-USP
}

\author{
Cristiane Aun Bertoldi* e Denise Dantas* \\ Faculdade de Arquitetura e Urbanismo da Universidade de São Paulo \\ * Autoras para correspondência: craun@usp.br; dedantas@usp.br
}

\begin{abstract}
RESUMO
Materialize é o acervo de materiais criado para auxiliar disciplinas dos cursos Design e Arquitetura e Urbanismo da FAU-USP, que contou com a parceria do Materiali e Design, coordenado pela Profa Dra Bárbara Del Curto, do Istituto Politecnico di Milano, e foi beneficiado por financiamento da Pró-Reitoria de Graduação da USP. Esse acervo digital poderá ser consultado on-line por docentes, alunos e pesquisadores, em plataforma aberta, com acesso irrestrito. Apresenta informações sobre características, qualidades e propriedades das amostras de materiais presentes no acervo, sua utilização, processos de transformação e fornecedores brasileiros. $\mathrm{O}$ acervo físico poderá ser consultado no LabDesign na FAU-USP, mediante agendamento.
\end{abstract}

Palavras-chave: Design de Produto; Materioteca; Material; Acervo; Material Didático.

\begin{abstract}
Materialize is the materials collection designed to support disciplines of the design course and the architecture and urbanism course at FAU-USP, which had a partnership with the Materiali and Design, coordinated by Barbara Del Curto, $\mathrm{PhD}$ of the Istituto Politecnico di Milano. This project received funding from the Pró-Reitoria de Graduação of USP. Teachers, students and researchers can visit this digital collection online with an open platform, and unrestricted access. The collection has information on the characteristics, qualities and features of the material samples, their use, the productive processes and the Brazilian suppliers. The physical materials collection can be consulted at LabDesign at FAU-USP, by appointment.
\end{abstract}

Keywords: Product Design; Materials Collection; Materials; Collection; Didactic Material.

\section{Introdução}

O pioneiro trabalho de Ashby e Johnson (2005, 2009 , 2010) aponta que os materiais possuem características e propriedades que perpassam diferentes níveis de qualidades. Existem as tangíveis e mensuráveis por instrumentos e por isso servem de indicadores do comportamento e desempenho dos materiais e objetivamente se prestam à orientação em especificações em projeto. Relacionam-se às propriedades físico-químicas e se situam nos domínios da engenharia dos materiais. Outras qualidades dos materiais apontadas pelo autor englobam assuntos próprios do campo do Design que são trabalhados ao longo da formação de estudantes de graduação em Design, e abarcam conhecimentos sobre fisiologia humana ligados à percepção sensorial e conhecimentos sobre linguagem nas suas dimensões sintática semântica, simbólica e pragmática, com a finalidade de orientação para a seleção de materiais em projetos.

As qualidades vinculadas à percepção sensorial dependem da estrutura da fisiologia humana e, apesar de detectáveis por instrumentos, têm no próprio homem seu melhor mediador e se relacionam com os órgãos dos sentidos, incluindo visão, tato, olfato, audição e paladar. A identificação de adequação de tais características materiais em um projeto muitas vezes se dá por comparação entre partes de um conjunto dado. As qualidades visuais dos materiais e de seus acabamentos superficiais englobam a variação cromática, com matizes, luminosidade e saturações distintas, as propriedades ópticas na variação entre transparência, translucidez e opacidade, as características superficiais 
variando de brilhante, acetinado, fosco, metalizado, fluorescente, furta-cor e outras. Pelo tato, existem as sensações de toque macio ou duro, seco e áspero ou sedoso acetinado, de quente e frio, de áspero, liso, rugoso, a percepção de texturas, de relevos, de peso ou leveza, de densidade, de rigidez e de maleabilidade. Pela audição, aspectos de som trazem variações que abrangem do metálico e estridente ao grave, abafado. Quanto aos sabores e odores, suas variações podem aparecer em gradações generalizadas, tais como: fortes, moderados, nulos ou agradáveis/desagradáveis, ou podem espraiar em variações mais detalhadas cujos parâmetros muitas vezes misturam sensações para identificar o percebido: cheiros adocicados, gostos metálicos etc.

Outras qualidades materiais identificadas por Ashby e Johnson $(2005,2009,2010)$ e aprofundadas na obra seminal de Manzini (2009) são aquelas relativas às construções culturais, organizadas por estruturas simbólicas, de representação. Referem-se a conhecimentos próprios de comportamento humano e psicologia e têm somente no homem o instrumento mensurador e avaliador. Aqui, o sentido de adequação das características materiais em projeto articula-se à intenção da mensagem que se pretende passar, exigindo domínio da linguagem. Considerar um material barato, vulgar, ou luxuoso e sofisticado faz parte dessa construção simbólica. Para isso, existe toda uma gama de variações de juízo acerca de um material, e, por fazerem parte das estruturas culturais, os valores são incrementais e alteráveis ao longo do tempo.

Foi nesse cenário de conhecimentos exigidos pelo campo do Design sobre propriedades físico-químicas, percepção sensorial e linguagem que o projeto Materialize se pautou. Os dados disponíveis nesse acervo digital e físico sobre materiais comtemplam os de ordem físico-química, que também se encontram em catálogos de fornecedores de amplo acesso a qualquer usuário. Como diferencial desse site, estão as informações sobre as possibilidades de transformação de cada material, informações sobre impactos ambientais e principalmente as características ligadas às qualidades sensoriais e de caráter interpretativo, vitais para o projeto em
Design e arquitetura. Ainda se ressalta a oportunidade de os usuários entrarem em contato direto com as amostras desse acervo, pois a maneira como estão organizadas em um mesmo lugar e as possibilidades de serem dispostas lado a lado de uma só vez permitem a comparação entre elas a fim de realizar-se a seleção de materiais para o projeto. Essa atividade de embate direto com materiais diversos é vital para a construção de repertório do aluno, para o desenvolvimento de linguagens para novos produtos, para a criação de novas interações com artefatos projetados por meio da especificação de determinado material.

Este artigo apresenta o projeto Materialize: acervo físico e digital de materiais da FAU-USP, idealizado para fornecer informações importantes para práticas projetuais nos cursos de Design e de Arquitetura da instituição, permitindo a realização de consultas em tempo real e a utilização do site durante as aulas de projeto e tecnologia.

Possuir um acervo próprio para uso no ensino de projeto amplia a capacidade de pesquisa. A parceria com o Istituto Politecnico di Milano possibilitou contar com a expertise de seus docentes, a troca de informações e ainda a autorização para uso e ampliação do sistema de classificação decimal de materiais desenvolvido por eles para adequação a necessidades dos dois cursos de graduação da FAU-USP.

No cenário brasileiro de ensino superior em Design existem outras pesquisas semelhantes vinculadas a cursos de graduação, como, por exemplo, a materioteca da Feevale, no Rio Grande do Sul, e a i-Matéria, vinculada à Unisinos. No âmbito internacional temos diversas iniciativas educacionais, como o Materiali e Design, do Istituto Politecnico di Milano, o Centre MAS - Matériaux Assemblages Systèmes (Matériauthèque), vinculado às graduações em Design e Arquitetura da Universidade de Montreal, a Matériauthèque da École National Supérieure D'Architecture Paris-Val De Siene e a materioteca da École Nationale Supérieure de Création Industrielle Les Ateliers, estas duas últimas em Paris (França), utilizadas para desenvolver workshops para os alunos nos ateliês da 
escola. Existem também importantes websites para consulta on-line com acesso restrito a associados e assinantes, como a norte-americana Material Connexion e a francesa MateriO, com foco em inovação. De acesso gratuito, existem o MateriaBrasil, com foco em produtos sustentáveis, a Polimérica e Materioteca, ambas iniciativas italianas, e ainda a Matweb, com informações técnicas sobre mais de 42 mil materiais. Muitos dos exemplos citados, entretanto, têm foco na engenharia de materiais e não apresentam os dados de modo adequado para sua aplicação em projetos de Design e Arquitetura. A grande maioria dos materiais inovadores encontrados em acervos digitais estrangeiros revela-se muito inspiradora quanto ao potencial de uso, mas não é possível encontrar seus fornecedores no Brasil, inviabilizando a especificação em projetos, já que implicam a importação de amostras.

Assim, o acervo Materialize surge para auxiliar disciplinas práticas, procurando dar acesso a informações necessárias para o projeto em arquitetura e em design, nos seus vários segmentos, projeto de produto, design de embalagens e projeto gráfico.

\section{Desenvolvimento}

A concepção e a implantação do projeto podem ser divididas em quatro eixos principais:

1. A criação da identidade visual do projeto e sua aplicação no site;

2. Pesquisa sobre informações técnicas de materiais e compatibilização de terminologia técnica em três línguas;

3. Critérios para seleção de amostras;

4. Procedimentos para contato com fornecedores e recepção das doações.

Cada uma das etapas listadas foi de fundamental importância para que o projeto mantivesse uma unidade.

A identidade visual do projeto é parte imprescindível para que este se torne conhecido no meio das escolas de design e também dos profissionais de São Paulo. Procurou-se criar uma marca que mantivesse vínculo com a instituição FAU-USP optando-se pelo uso das cores ocre e cinza, presentes em sua arquitetura. A estrutura do site também buscou manter essa identidade, de modo a reforçá-la. A identidade visual foi criada por Thabata Fernanda Oliveira, estagiária do projeto, sob supervisão das autoras.

Na etapa inicial do processo, foi necessário que se fizessem a coleta e o tratamento de informações referentes ao conteúdo de conhecimentos sobre materiais e processos, tomando-se como base termos utilizados no sistema de classificação decimal de materiais desenvolvido pelo Materiali e Design do Politecnico di Milano. Esse sistema foi apresentado em italiano, e parte do conteúdo foi traduzida para o inglês. Foi necessário realizar a tradução dos termos restantes do italiano para o inglês e depois de todos os termos para o português. Para isso, foi utilizada uma bibliografia de apoio sobre materiais e processos para Design, com destaque para o livro de Ashy que possui versões nas três línguas: Ashby e Johnson (2009) - versão em inglês; Ashby e Johnson (2005) - versão em italiano; e Ashby e Johnson (2010) - versão em português. Outros livros foram consultados: Lima (2006), Lesko (2004), Bann (2010) e Rossi Filho (2001). Essa etapa contou com a colaboração da professora Cyntia dos Santos Malaguti de Souza e do estagiário Lucas Marques Otsuka, além das autoras deste artigo.

A seleção de fornecedores de amostras de materiais foi feita a partir de critérios estabelecidos pela equipe, para garantir que não fossem adquiridos materiais relacionados àqueles em extinção ou em risco de extinção, a menos que fossem provenientes de fornecedores com certificado de manejo sustentável, assim como para assegurar que não fossem materiais perigosos, tóxicos, ilegais, perecíveis, valiosos ou caros (o que tornaria o acervo vulnerável a roubos), acondicionados na forma líquida (pois muitos produtos líquidos são perecíveis e podem ser combustíveis e inflamáveis, principalmente tintas e vernizes). Também se considerou inadequada a aquisição de produtos acabados, como objetos ou sistemas estruturais fechados, tais como, por exemplo, sistemas de pisos elevados ou embalagens metálicas já configuradas. Isso foi observado para atender às especificidades 


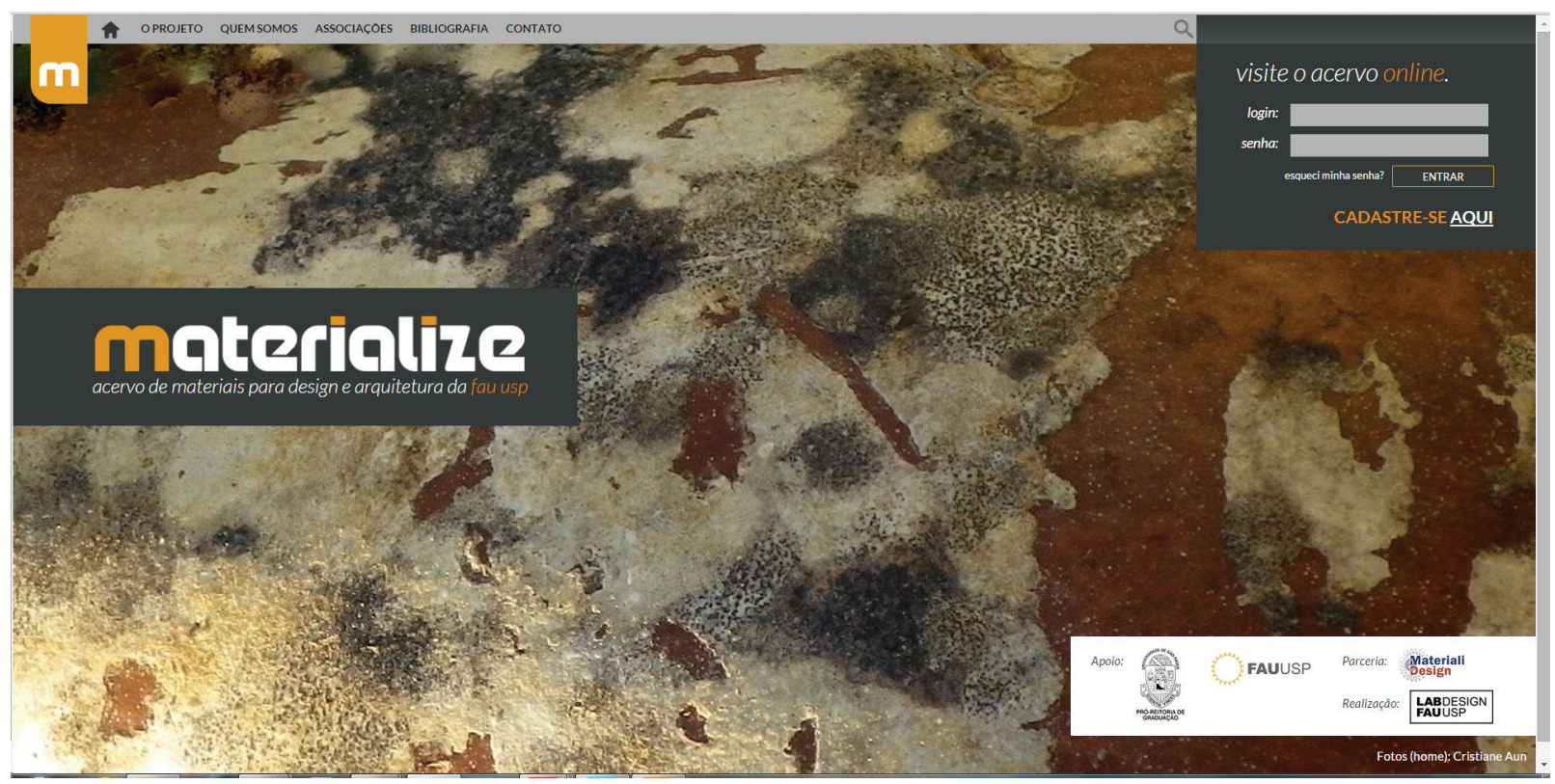

Figura 1 - Página principal do site Materialize.

do projeto, que tem como objetivo apresentar materiais para uso em projetos e não materiais já conformados ou já aplicados em sistemas prontos. Outro critério relevante relacionava-se à quantidade máxima de amostras de determinado tipo de material, pois não se pretende abrigar coleções e sim exemplos expressivos e significativos, no que tange às qualidades sensoriais em função da cor, textura, superfície, propriedades ópticas e decoração/padrão.

Para esses critérios sensoriais, decidiu-se, quanto à cor, que as amostras poderiam variar em preto, branco, cinza médio, cor saturada quente, cor saturada fria, cor insaturada clara e insaturada escura. Em relação à textura, foram considerados: liso, baixo relevo, alto relevo e relevo cavado. Quanto à aparência de sua superfície, valeram os seguintes critérios: brilhante, acetinada, fosca, iridescente/furta-cor, metalizada. Quanto às propriedades ópticas: opaca, translúcida, transparente. E quanto à decoração padrão: liso, listrado, geométrico, figurativo realista, figurativo estilizado e abstrato/manchado. Esses critérios auxiliaram a buscar amostras que possuíssem variedade em cada um deles, tentando estabelecer múltiplas percepções para os estudantes.

As pesquisadoras responsáveis pelo projeto definiram procedimentos de busca de fornecedores de amostras, tornando possível a geração de uma lista de possíveis empresas localizadas preferivelmente 16 em regiões mais próximas de São Paulo para facilitar a expedição e viabilizar a implantação do projeto piloto, que não contava com verba para coleta de amostras ou para pagamento pelo transporte.

Foram necessárias também a definição e a geração de um protocolo de condutas de abordagem durante o contato com empresas para a solicitação de doação de amostras, a partir da padronização da sequência de procedimentos usados na interlocução com cada empresa em questão. Padronizou-se também o recebimento e a conferência das amostras, assim como da carta de doação em conformidade com o conteúdo doado, para garantia de controle de fluxo de recebimento, para registro das informações em acordo seguido de arquivamento da carta de doação, ou para a realização de novo contato para solicitação de dados faltantes. Esses procedimentos tornaram-se importantes para que todo o processo fosse padronizado e cumprisse as exigências da legislação brasileira para doações à universidade pública naquele momento. Atualmente, o acervo conta com 640 amostras, recebidas de sete fornecedores brasileiros.

\section{Configuração da Base de Dados Centrada na Prática Projetual}

A configuração da base de dados considerou sistemas de busca mais intuitivos e adequados 
às práticas projetuais de designers e arquitetos, a partir das recomendações de Campos e Dantas (2008a). O sistema de classificação decimal de materiais utilizado para o Materialize é o empregado pelo Materiali e Design (Politecnico di Milano), porque tem quinze anos de existência e aplicação, e foi testado e implantado em um ambiente acadêmico. Além disso, por esse sistema utilizado seguir uma classificação decimal, possibilita a inclusão de novas subcategorias, permitindo maior especificidade na inserção dos dados sobre materiais e ampliação conforme necessário.

O sistema original conta com as seguintes categorias: metais, cerâmicas, materiais naturais, compósitos, polímeros, materiais estratificados, têxteis, materiais reciclados, materiais funcionais/inteligentes, tintas e vernizes. Ao ser analisado mais atentamente para adoção, verificou-se que esse sistema não estava plenamente adequado às necessidades da FAU-USP, pois algumas categorias de materiais muito utilizadas em nossos cursos não eram contempladas nas subcategorias existentes. Foi necessária a inclusão de algumas novas subcategorias de materiais, como em cerâmicas e vidros, papéis e tintas e vernizes, fundamentais para os setores editoriais, de embalagens e de arquitetura. Essa revisão e a ampliação foram feitas mediante acordo com a professora Barbara Del Curto.

As características da base de dados foram definidas a partir da análise de outras bases descritas em Campos e Dantas (2008a), e os requisitos envolveram a adequação às necessidades didáticas, a fácil manutenção e a busca por experiências de navegação e design de interface amigáveis.

O acesso ao sistema de busca pelo usuário é feito por meio de login e senha, após cadastro. $\mathrm{O}$ website possui ferramentas de consulta que incluem um sistema de busca simples por termo (tags), ou por listagem geral de materiais, por listagem de taxonomias de materiais e por busca cruzada entre as taxonomias dos materiais. O usuário pode contribuir com indicações de materiais ou fornecedores nacionais, ou divulgar resultados de pesquisa sobre o assunto. Cada categoria de material foi indexada a uma cor, possibilitando que tanto a busca como o resultado sejam mais facilmente identificados quanto à categoria a ele associada.

Cada amostra de material inserido no sistema é classificada conforme o sistema decimal descrito anteriormente e, a partir dessa classificação, para cada material é gerado um número. A padronização da apresentação dos materiais aos usuários se dá por uma ficha catalográfica que contém: nome do material, classificação, número de catalogação para a localização da amostra no acervo físico, ícone de apresentação formal da amostra, até cinco imagens da amostra, texto explicativo contendo suas características físicas e perceptivas, ano de obtenção da amostra, usos mais frequentes, além de informações técnicas fornecidas pelo fabricante ou pela literatura técnica especializada. Também se indica o fornecedor da amostra com link para seu website.

As imagens das amostras disponibilizadas no sistema foram feitas no FotoFAU. Foi necessário estabelecer critérios para esse registro fotográfico, em relação à quantidade e à qualidade de resolução e tipo de informação visual desejada para cada amostra e/ou conjunto de amostras. A coordenação do projeto realizou um documento com parâmetros para a execução dos registros fotográficos. Depois, foram selecionadas as cinco imagens que melhor apresentavam as características de cada amostra, a partir da comparação da amostra com as imagens quanto à similaridade e expressividade.

A equipe do Materialize realizou o tratamento e a edição de mais de 3 mil fotos de amostras de materiais selecionados, utilizando um programa de edição de imagens para a padronização do tamanho da imagem para web, melhoria de enquadramento, ajuste de níveis, contraste, brilho e curvas, e correção de imperfeições.

Inicialmente, procurou-se disponibilizar informações de materiais convencionais, de modo a mesclar dados para os mais diversos tipos de uso em projeto. Entrou-se em contato com fabricantes para solicitar doação de amostras e catálogos e, após o recebimento, cada amostra foi devidamente classificada e identificada, recebendo uma codificação criada a partir de princípios do sistema de biblioteca da tabela Cutter-Sanborn (2017), conforme exemplo a seguir. 


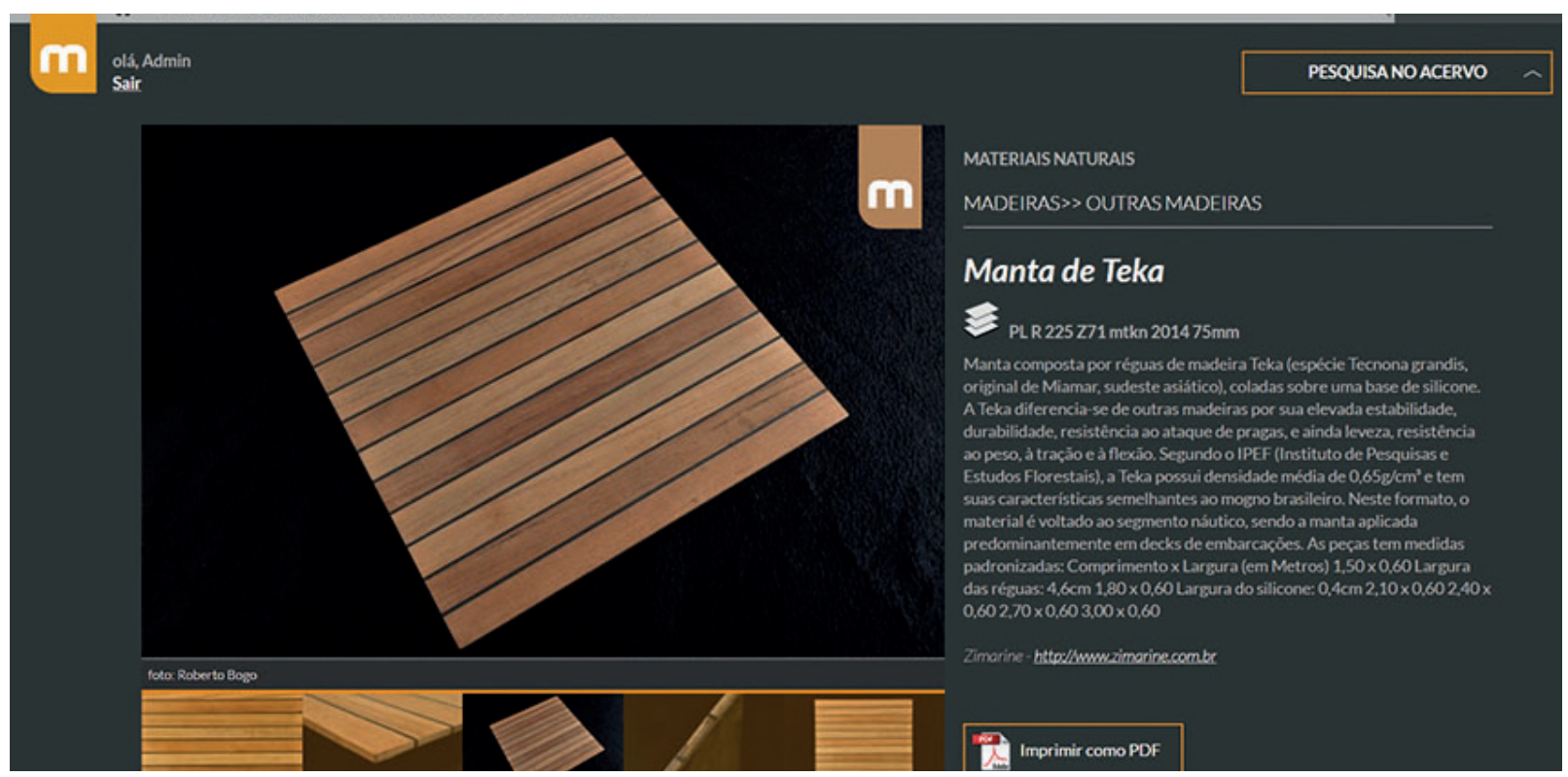

Figura 2 - Resultado de busca de amostra no site Materialize.

Esse sistema permitiu que a organização do acervo físico tivesse total correspondência com o sistema digital, facilitando a retirada e o reposicionamento correto do material nas estantes.

Para as páginas iniciais do site http://www. materialize.fau.usp.br foi feito o registro fotográfico de 44 imagens de materiais variados diferentes de qualquer amostra recebida, valorizando-se qualidades visuais e táteis, que apareciam na home page do site em sequência randômica. Desse modo, conseguiu-se expressar plasticamente o conceito principal do site revelando-se o interesse nas qualidades sensíveis do mundo material.

Além da página principal, o site possui uma página na qual se explicam o projeto e seus objetivos, apresenta resumidamente os envolvidos no projeto e seu papel na implantação desse piloto, uma lista de associações relacionadas a materiais que foram consultadas durante o desenvolvimento do projeto, a bibliografia utilizada e uma página para contato, que permite enviar sugestões, críticas, marcar visitas ao acervo físico ou indicar novos materiais a serem incorporados no acervo.

\section{Configuração do Acervo Físico Centrada na Prática Projetual}

Foram feitas simulações sobre a maneira como os usuários poderiam fazer a busca por materiais. Procurou-se acompanhar o fluxo de ações a fim de compreender as possibilidades e limitações de arranjos. Essas ações serviram para definir e justificar o modelo de catalogação adotado, elaborado pelas autoras.

A disposição das amostras no Materialize foi organizada a partir de sua configuração formal, seguindo a lógica mais frequente de busca para projetos em Design, segundo características desejadas. $\mathrm{O}$ agrupamento próximo de materiais com a mesma configuração formal permite ao aluno a comparação sensorial dos mesmos, estabelecendo outros critérios para a seleção que ultrapassam suas características físico-químicas e se atrelam a aspectos perceptivos e simbólicos. As categorias formais utilizadas também foram feitas em parceria com o Materiali e Design, e consistem em: amorfo, aplicação e tratamento superficial, longo rígido, longo flexível, plano rígido, plano flexível, particulados, tridimensional simples e tridimensional complexo.

Cada amostra, após catalogada e inserida no sistema, recebe uma etiqueta com seu número na cor da sua categoria. Desse modo, com base na codificação cromática, será possível saber, ao consultar o acervo físico, se aquela amostra é da categoria dos metais, das cerâmicas, se é um material natural, e assim por diante.

A justaposição de amostras de classificação distintas é o principal diferencial desse acervo. Apesar de não contar ainda com mobiliário específico que 


\begin{tabular}{|c|c|c|c|}
\hline Campo & Código & A que se refere & \\
\hline 1 & PL R & Plano Rígido & Configuração formal \\
\hline 2 & 115.1 & $\begin{array}{l}\text { Cerâmica/ outras cerâmicas } \\
\text { tradicionais / Grês }\end{array}$ & SDCM - classificação do material \\
\hline 3 & L599 & Lepri & Notação do fornecedor \\
\hline 4 & esb & eco slim bianchetto & $\begin{array}{l}\text { Código de especificação da } \\
\text { amostra }\end{array}$ \\
\hline 5 & 2014 & Ano & Recebimento da amostra \\
\hline 6 & $11 \mathrm{~cm}$ & Tamanho & Especificidade da amostra \\
\hline
\end{tabular}

Tabela 1 - Exemplo de código gerado para uma amostra de material pelo Sistema de Catalogação de Amostras de Materiais por Configuração (SCAMC).

\begin{tabular}{|c|c|c|c|}
\hline ID - & Nome do Material & Codigo & Categoria \\
\hline 65 & Cantoneira Paglia & PL R 115.1 L599 can 2014 pa50mm & GRÉS \\
\hline 50 & Chapas Antirreflexivas AD & PL R 411.05 C346 adcol $2014 \mathrm{ce} 2$ & PMMA (Polimetilacrilato) \\
\hline 51 & Chapas Antirreflexivas AR & PL R 411.05 C346 arcol 2014 c1 & PMMA (Polimetilacrilato) \\
\hline 52 & Chapas com PVC & PL R 411.05 C346 pccol 2014 c1 & PMMA (Polimetilacrilato) \\
\hline 48 & Chapas Perolizadas & PL R 411.05 C346 plcol 2014 c2 & PMMA (Polimetilacrilato) \\
\hline 49 & Chapas Pintadas & PL R 411.05 C346 picol 2014 c1 & PMMA (Polimetilacrilato) \\
\hline 20 & Ecoslim Bianchetto & PL R 115.1 L599 esb $201411 \mathrm{~cm}$ & GRÉS \\
\hline 33 & EPDM 71 & PL F 432.06 H149 epdm71 2014 p10mm & Outras borrachas termoplásticas \\
\hline 34 & EVA 1269 & PL F 432 H149 eva 2014 a 1269 & Borrachas termoplásticas \\
\hline 63 & Invecchiatto Champagne & PL R 115.1 L599 inv $2014 \mathrm{ch} 11 \mathrm{~cm}$ & GRÊS \\
\hline 60 & Invecchiatto Cioccolato & PL R 115.1 L599 inv 2014 ci11cm & GRÉS \\
\hline 59 & Invecchiatto Nero & PL R 115.1 L599 inv 2014 ne $11 \mathrm{~cm}$ & GRÉS \\
\hline 62 & Invecchiatto Paglia & PL R 115.1 L599 inv 2014 pa $11 \mathrm{~cm}$ & GRÊS \\
\hline 61 & Invecchiatto Rosso & PL R 115.1 L599 inv 2014 ro $11 \mathrm{~cm}$ & GRĖS \\
\hline 37 & Manta de Teka & PL R $225 \mathrm{Z71}$ mtkn $201475 \mathrm{~mm}$ & Outras madeiras \\
\hline
\end{tabular}

Tabela 2 - Exemplo de interface do sistema de inserção de amostras e os códigos de classificação de amostras de materiais por configuração.

possa apresentar as amostras de forma a potencializar o processo criativo dos alunos, o arranjo proposto viabiliza a implantação do projeto em espaço reduzido e sem a necessidade de aumento de custos para aquisição de mobiliário especial.

A gestão do espaço físico para permitir sua abertura durante o horário regular das aulas está em fase de ajustes junto à biblioteca da FAU-USP, que poderá vir a gerenciar a visita a esse espaço e o controle do acesso aos materiais do acervo.

\section{Conclusão}

A implementação desse projeto piloto exigiu a realização de estudos a respeito de princípios de funcionamento de sites, da estrutura de navegação, da dinâmica de uso de espaços de acervos físicos, de aspectos de comunicação com o usuário do acervo e com programadores. Esses estudos foram fundamentais para gerar reflexões sobre o significado de um acervo no âmbito do ensino e acerca da quantidade e qualidade das informações divulgadas em relação à abrangência e à profundidade de conteúdo.

Esse projeto piloto reuniu muito material produzido e está em fase final de implantação. Há importantes conteúdos sobre princípios para o desenho de acervos de materiais que foram publicados, assim como para o planejamento de estrutura de navegação de sites de acervos digitais.

Verificou-se que a criação de um acervo de materiais e sua manutenção constituem um processo 


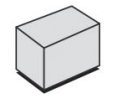

$\mathrm{TH}$

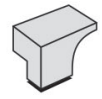

TC

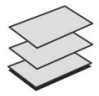

PLR

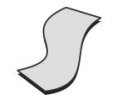

PLF

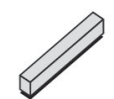

LO R

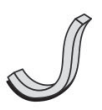

LOF
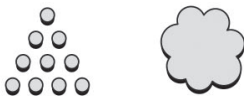

PA

AM<smiles>C1CC2CC12</smiles>

ATS A

Figura 3 - Ícones desenvolvidos para a classificação formal das amostras.
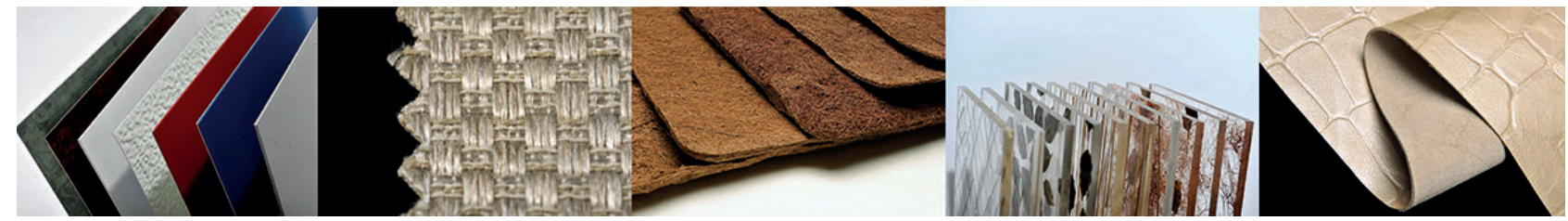

Figura 4 - Exemplos de amostras de materiais fotografadas e inseridas no site.

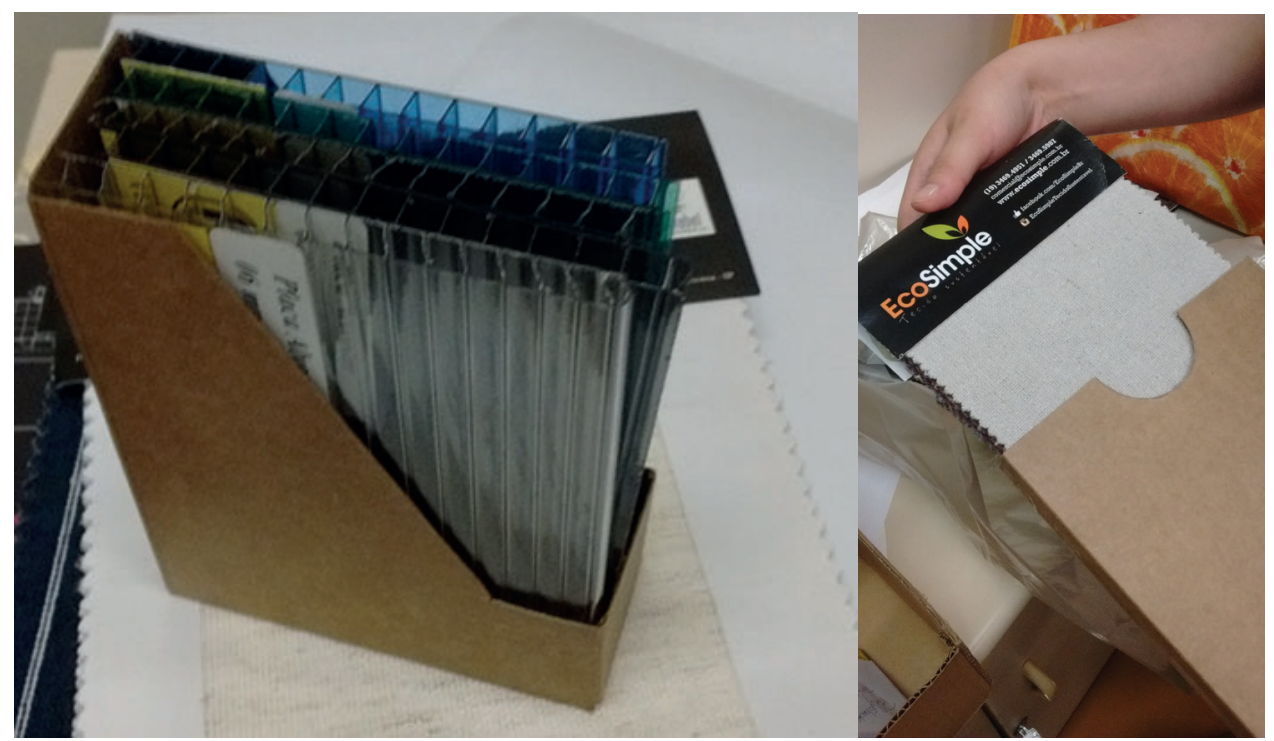

Figura 5 - Exemplos de amostras de materiais para consulta no acervo.

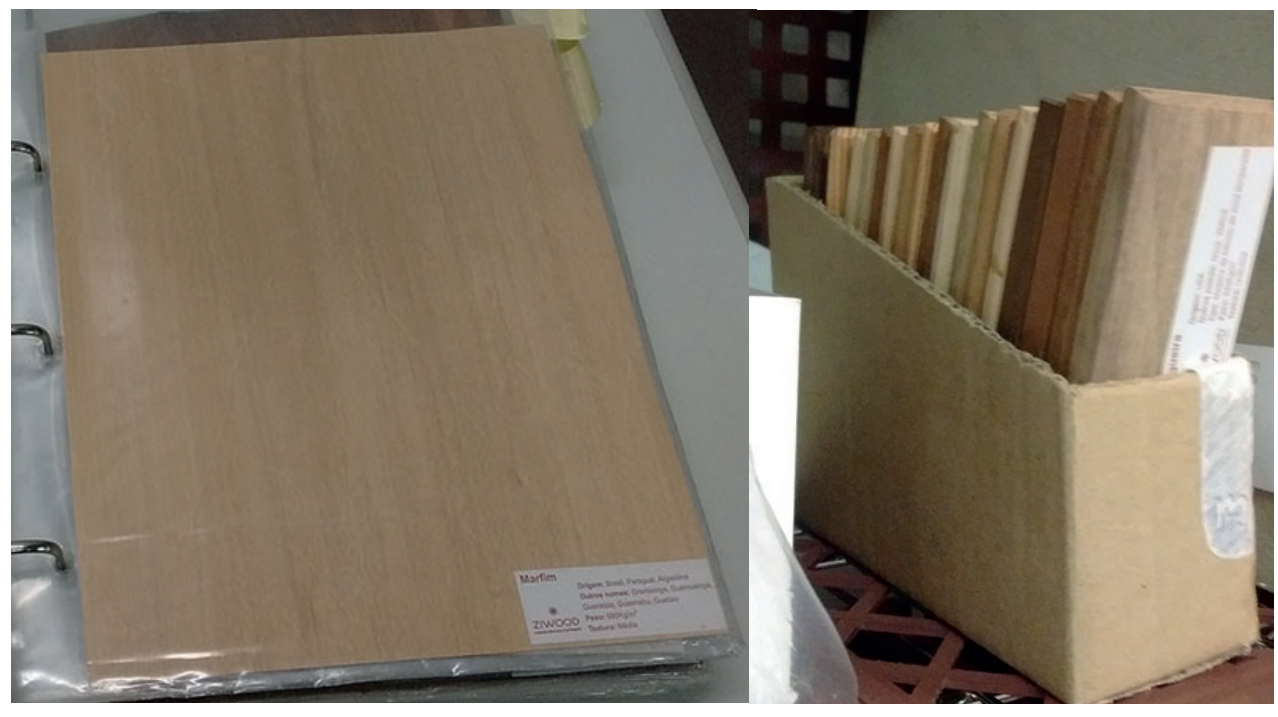

Figura 6 - Exemplos de diferentes configurações de amostras de madeira. À esquerda: folhas de madeira (plano flexível), e à direita: amostras de madeira maciça (plano rígido). 
complexo e que a parceria com o Istituto Politecnico di Milano, através da professora Barbara Del Curto, foi de extrema importância para facilitar essa implantação. Espera-se que com a apresentação deste artigo haja interesse na realização de novas parcerias entre instituições de ensino e pesquisa em Design e Arquitetura em âmbito nacional e internacional.

\section{Agradecimentos}

As autoras gostariam de agradecer à Pró-Reitoria de Graduação da USP e à FAU-USP.

\section{Créditos das Imagens}

Cândida Maria Vuolo, Cristiane Aun Bertoldi, Denise Dantas e Roberto Bogo.

\section{Referências Bibliográficas}

ASHBY, M. F. \& JOHNSON, K. Materiali e Design. L'Arte e la Scienza della Selexione dei Materiali per il Progetto. Milano: Casa Editrice Ambrosiana, 2005.

. \& . Materials and Design: The Art and Science of Material Selection in Product Design. Oxford: Butterworth-Heinemann, 2009.

.\&__. Materiais e Design: Arte e Ciência da

Seleção de Materiais no Design de Produto. Rio de Janeiro: Campus, 2010.
BANN, D. Novo Manual de Produção Gráfica. Porto Alegre: Bookman, 2010.

CAMPOS, A. P. de \& DANTAS, D. "M+D: Conceptual Guidelines for Compiling a Materials Library". Undisciplined! Design Research Society Conference. Proceedings of DRS2008, Design Research Society Biennial Conference. Sheffield: Sheffield Hallam University, 2008a. Trabalho apresentado, pp. 1-18. Disponível em: $\langle$ http://shura.shu.ac.uk/509/1/fulltext.pdP $>$. Acessado em 7 maio 2017.

DANTAS, D. \& CAMPOS, A. P. de. "Análise Comparativa de Materiotecas: Recomendações para a Construção de Modelos Acadêmicos". Congresso Brasileiro de Pesquisa e Desenvolvimento em Design / P৬D Design ( $8^{\circ}$, São Paulo). São Paulo: Aend Brasil, 2008b. Trabalho apresentado, pp. 56-72.

LESKO, I. Design Industrial: Materiais e Processos de Fabricaşão. São Paulo: Edgard Blucher, 2004.

LIMA, M. A. Introdução aos Materiais e Processos para Designers. São Paulo: Ciência Moderna, 2006.

MANZINI, E. The Material of Invention. Cambridge, Massachusetts: The MIT Press, 1989.

ROSSI FILHO, S. Graphos: Glossário de Termos Técnicos em Comunicação Gráfica. São Paulo: Cone Azul, 2001.

TABELA Cutter-Sanborn: Versão Online em Unforbi (website), 2017. Disponível em: <http://www.unforbi. com.ar/herramientas/tablascutter/cutterABC.html $>$. Acessado em 7 maio 2017.

Publicado em 30/06/2017. 